\title{
Automatic load sharing of distribution transformer for overload protection
}

\author{
Abraham Hizkiel Nebey*
}

\begin{abstract}
Objective: Load sharing provides sufficient protection to distribution transformer under overloaded conditions. Due to overload on transformer, the efficiency drops and windings get overheated and may burn. By sharing a load current on transformer for each phase the transformer was protected. Therefore, the objective of this study was to protect transformers from overloaded conditions by sharing the load.
\end{abstract}

Result: The system automatically connects and disconnects switch to share the transformer loads. The controller was managed the load according to rules.

Keywords: Transformer overload, Fuzzy logic controller, Dangila, Mat lab/Simulink

\section{Introduction}

Overloading protection means detecting problems with distribution transformer and isolating from the load. Fuzzy logic controller is an intelligent tool that serves as an overloading protection for distribution transformers. It has logical rules which protects distribution transformers against overloading conditions [1].

Overloading protection for the distribution transformer can reduce around 20\% of electric power interruption [2]. Protection and overloading protection in a particular, is one of the measurement strategies to improve power system's reliability status.

In Ethiopia, many customers were suffering from electric power interruptions. There were many malfunctions distribution transformers in Dangila town. Major causes of this malfunction of the distribution transformer was overloading conditions which can be easily prevented through overloading protection [3-5]. Currently, the practice of overloading protection in Ethiopia is low [3, $6,7]$.

Even though the government of Ethiopia developed strategies for energy supply, there is the varying level of

*Correspondence: hizkielabraham@yahoo.com

Bahir Dar University Institute of Technology, P.O.Box 26, Bahir Dar, Ethiopia intervention were being given both at the community level and energy centres [8]. The efforts were not organized at the level of practice and this is due low number of researches to explore overloading protection in Ethiopia [9-11]. Therefore, the aim of this study was to protect the distribution transformers in Dangila town, Ethiopia.

\section{Main text}

Methods

\section{Study setting and period}

A Failure Modes and Effects Analysis were conducted in Dangila town from April 1 to June 3, 2019. Dangila is the capital city of Dangila woreda in Amhara regional state. It is $78 \mathrm{~km}$ away from Bahir Dar which is the capital city of Amhara regional state. The city has five sub towns, one substation, which gives serves to the town and the surrounding people.

Questionnaires were distributed to Ethiopia Electric Utility maintenance staffs. The questionnaire assesses the consequences of failures in terms of electric power interruption, damage of the components or further damage of subsequent sub systems.

\section{Measurement}

Data were collected using interview and direct measurement. The questionnaire was prepared to collect 
the relevant data $[3,12]$. Two weeks were given for data collectors and supervisors for 3 days on methods of extracting the information through interviewing, and direct measurement.

\section{Mathematical modelling for determining KVA ratings}

There were a mathematical equation for determining KVA rating of transformer, one and two.

From the collected data following parameters were calculated.

\section{For load assessment area of A}

Real power

$$
\begin{aligned}
\mathrm{P} & =(175020+14700+34000+4050) \mathrm{W} \\
& =227770 \mathrm{~W} \\
& =227.770 \mathrm{~kW}
\end{aligned} .
$$

From this the load current can be calculated

$$
\begin{aligned}
\mathrm{I}_{\mathrm{L}} & =\frac{\text { real power }}{\sqrt{3} * V s * p f} \\
& =\frac{227770 \mathrm{~W}}{1.73 * 380 * 0.8}=\frac{227770 \mathrm{~W}}{526 \mathrm{~V}}=433 \mathrm{~A}
\end{aligned}
$$

Then to find the KVA rating of the transformer A,

$$
\begin{aligned}
\mathrm{KVA}_{\mathrm{A}} & =\frac{\text { real power }}{P F} \\
& =\frac{227.770}{0.8} \mathrm{~kW}=285 \mathrm{KVA} .
\end{aligned}
$$

From this the transformer rating was selected. For safety purposes and expansion, in case more loads were added at a later date. Therefore, transformer rating was approximately 315 KVA.

\section{For load assessment area of $B$}

In similar way:

Rated power were the sum of the entire total load that delivered to the consumer.

$$
\begin{aligned}
\text { Real power } & =(18340+187285+34000) \mathrm{W} \\
& =239625 \mathrm{~W} \\
& =23.9625 \mathrm{KW}
\end{aligned} .
$$

From these load currents was calculated as;

$$
\begin{aligned}
\mathrm{I}_{\mathrm{L}} & =\frac{\text { real power }}{\sqrt{ } 3 * \mathrm{vs} * \mathrm{pf}} \\
& =\frac{23.9625 \mathrm{KW}}{1.73 * 380 \mathrm{v} * 0.8 \mathrm{~V}}=\frac{23.9625 \mathrm{KW}}{526 \mathrm{~V}}=455.5 \mathrm{~A} .
\end{aligned}
$$

Then to find the KVA rating of the transformer $\mathrm{B}$

$$
\begin{aligned}
\mathrm{KVA}_{\mathrm{B}} & =\frac{\text { Real power }}{P F} \\
& =\frac{242.245 \mathrm{KW}}{0.8}=303 \mathrm{KVA} .
\end{aligned}
$$

From this the transformer rating was selected above this value because the transformer rating was greater than the actual load. This was done for safety purposes and expansion, in case more loads were added at a later date. Therefore, the transformer rating was approximately 315 KVA.

Mathematical modelling of two load sharing of transformers Two transformers of equal voltage ratios were selected for working in parallel. This can avoid a circulating current between the transformers [13-16].

From the above (Fig. 1) circuit the following parameters were calculated.

$$
\mathrm{I}_{\mathrm{A}} \mathrm{Z}_{\mathrm{A}}=\mathrm{I}_{\mathrm{B}} \mathrm{Z}_{\mathrm{B}}=\mathrm{I}_{\mathrm{L}} \mathrm{Z}_{\mathrm{L}}=\mathrm{V}(\text { say })
$$

$$
\mathrm{Z}_{\mathrm{A}}=\mathrm{R}_{\mathrm{A}}+\mathrm{X}_{\mathrm{A}}
$$

$$
\mathrm{Z}_{\mathrm{B}}=\mathrm{R}_{\mathrm{B}}+\mathrm{X}_{\mathrm{B}}
$$

Here,

$$
\mathrm{I}_{\mathrm{L}}=\mathrm{I}_{\mathrm{A}}+\mathrm{I}_{\mathrm{B}}
$$

And $Z_{\text {equ }}$ is the equivalent impedance of the two transformers given by,

$$
\mathrm{Z}_{\text {equ }}=\frac{\mathrm{Z}_{\mathrm{A}} \mathrm{Z}_{\mathrm{B}}}{\mathrm{Z}_{\mathrm{A}}+\mathrm{Z}_{\mathrm{B}}}
$$

From Eqs. (5), (6) and (7)

$$
\mathrm{I}_{\mathrm{A}}=\frac{V}{Z_{\mathrm{A}}}=\frac{I_{\mathrm{L}} Z_{\mathrm{L}}}{Z_{\mathrm{A}}}=I_{\mathrm{L}} \frac{Z_{\mathrm{B}}}{Z_{\mathrm{A}}+Z_{\mathrm{B}}}
$$

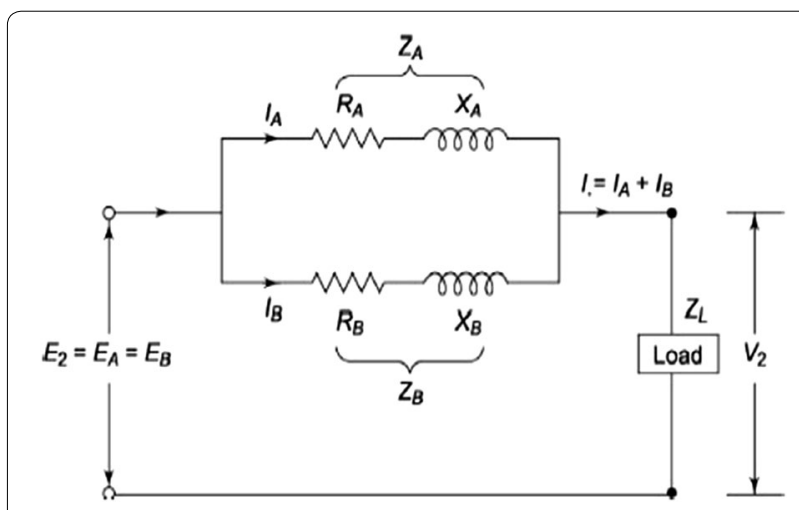

Fig. 1 Equivalent circuits of parallel transformers 


$$
\mathrm{I}_{\mathrm{B}}=\frac{V}{Z_{\mathrm{B}}}=\frac{I_{\mathrm{L}} Z_{\mathrm{L}}}{Z_{\mathrm{B}}}=I_{\mathrm{L}} \frac{Z_{\mathrm{A}}}{Z_{\mathrm{B}}+Z_{\mathrm{A}}}
$$

From the above it has seen that the transformer with higher impedance supplies lesser load current and vice versa. If transformers of dissimilar ratings were paralleled the transformer with a larger rating shall have a smaller impedance as it has to produce the same drop as the other transformer, on a larger current. Thus the ohmic values of the impedances must be in the inverse ratio of the ratings of the transformers.

$$
\mathrm{I}_{\mathrm{A}} \mathrm{Z}_{\mathrm{A}}=\mathrm{I}_{\mathrm{B}} \mathrm{Z}_{\mathrm{B}} \text {, therefore } \frac{\mathrm{I}_{\mathrm{A}}}{\mathrm{I}_{\mathrm{B}}}=\frac{\mathrm{Z}_{\mathrm{B}}}{Z_{\mathrm{A}}}
$$

\section{Modelling of fuzzy logic base protective relay}

The Fuzzy logic interface (Additional file 1: Figure S1) was used to make decisions [17-19]. Thus it is more precise than conventional relaying techniques. The Fuzzy logic controller was an intelligent tool to manage the loading condition, so as to protect transformers from overload conditions.

The proposed fuzzy logic based input was defined as:

$\mathrm{T}_{1 \mathrm{~L}}$, represents the load of transformer one.

$\mathrm{T}_{2 \mathrm{~L}}$, represents the load of transformer two.

\section{Membership function for proposed control}

The membership function defined how the input is mapped to member values [20-23].

$\mathbf{T}_{1 \mathrm{~L}}$, represents the membership function load of transformer one (Additional file 2: Figure S2). It consists small, medium and large.

$\mathbf{T}_{2 \mathrm{~L}}$, represents the membership function load of transformer Two (Additional file 3: Figure S3). It consists small, medium and large.

The output power was membership functions of the proposed control system (Additional file 4: Figure S4). The output linguistic values were not shared, share, and trip (Table 1).

\section{Proposed control rule}

The control rule content was linguistic variables [24-27]. These linguistic descriptions take from if then rule. The proposed control had nine rules for transformer overloading protection that consist input antecedents and consequences of output (Additional file 5: Figure S5). The rules are shown in (Fig. 2).
Table 1 Rule base of transformer load

\begin{tabular}{llll}
\hline $\mathbf{T}_{\mathbf{2} \mathbf{L}}$ & $\mathbf{T}_{\mathbf{1 L}}$ & & \\
\cline { 2 - 4 } & Small & Medium & Large \\
\hline Small & Not share & Not share & Share \\
Medium & Not share & Not share & Share \\
Large & Share & Share & Trip \\
\hline
\end{tabular}

\section{Overall controller system}

Transformer load one and transformer load two were the input parameters of the controller. $\mathrm{T}_{1 \mathrm{~L}}$ and $\mathrm{T}_{2 \mathrm{~L}}$ indicates the load of transformer one and load of transformer two respectively. The load for each transformer was assumed to the Gaussian random signal generator. The multiport conditional switch (Additional file 6: Figure S6) will take an action according to the rules written and loaded in the fuzzy logic controller.

\section{Operational definition}

Overloading protection: If power system protection were used to protect the distribution transformer from overloading conditions [20, 28-31].

\section{Result and discussion Simulation result}

The controller looks the load on transformer first and made decisions (not share, share and trip) to protect transformers. Therefore, there was no equipment failure and power interruption due overloading conditions.

In order to evaluate the performance of rule based load sharing system, three various types of loads were applied at the output of the distribution transformer

Case (I): The two transformers were at normal state. When the two transformers were at normal state, during this time the sharing relay was not energized because it feeds its load at normal state.

Case (II): when one of the transformers was overloaded.

When one transformer was at normal state and another was overloaded, at this condition the sharing relay was energized to share the load.

Case (III): The two transformers were overloaded for each phase.

When two transformers were overloaded, at this condition the relay will trip to protect transformers. 


\section{Rule Editor: Abraham.f}

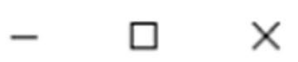

File Edit View Options

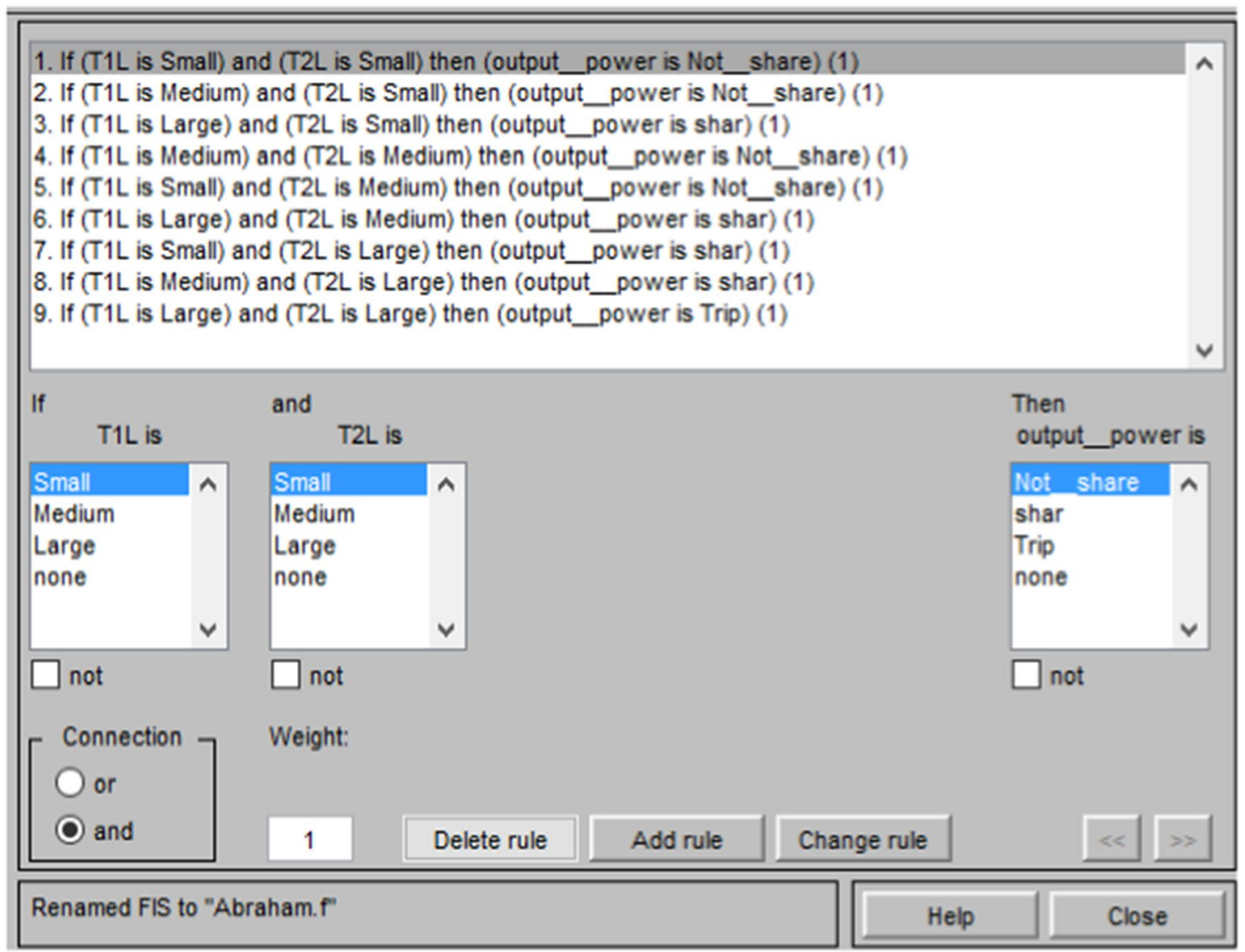

Fig. 2 Rule editor

\section{Conclusion}

The work was all about how to supply power intelligently manage an overload condition. The system automatically connects and disconnects switch to share the transformer loads. Most of the villages were suffering with electric instructions. This was due to transformer failure. A recommendation to decrease power interruption in the town was: Load sharing of transformer to protect from failures. This load sharing was modelled to the town; therefore, this transformer load sharing system was the best solution to protect equipment failure and electric instructions.

Intelligent controller was used to make intelligent decisions by sensing amount of the load on the transformer. Rule base fuzzy logic controller manages the load and transformers were protected from overload condition.

\section{Limitations}

1. Possible demand growth rate with population and economic growth rate (load forecasting).

2. Further study can be carried out for sensing fault current, surge voltage (consider more parameters).

\section{Supplementary information}

Supplementary information accompanies this paper at https://doi. org/10.1186/s13104-019-4880-1.

Additional file 1: Figure S1. Fuzzy logic interface model.

Additional file 2: Figure S2. Membership functions of transformer load one.

Additional file 3: Figure S3. Membership functions of transformer load two. 
Additional file 4: Figure S4. Membership functions of output power.

Additional file 5: Figure S5. Rule evaluations.

Additional file 6: Figure S6. Overall protection systems for overloading protection/interface.

\section{Abbreviations}

KVA: kilo volt ampere; KWh: kilo Watt hour; P: real power

\section{Acknowledgements}

My deepest gratitude goes to Bahir Dar University Institute of Technology, Faculty of Electrical and Computer Engineering for giving this chance to conduct this research. I am grateful to all friends for particularly supporting in this article.

\section{Authors' contributions}

AHN, contributed to the design of this study. Author conceived and design study, collected, modelled, analyzed and interpreted data. AHN drafted the manuscript for important intellectual content. The author read and approved the final manuscript.

\section{Funding}

No fund.

\section{Availability of data and materials}

The date of this study will not be shared publically due to the presence of sensitive (confidential) participants' information.

\section{Ethics approval and consent to participate}

Ethical approval of the study was obtained from Bahir Dar University, Faculty of Electrical and Computer Engineering of Electrical power ethical review committee. The ethical letter was submitted to Bahir Dar, Ethiopia electric power Utility (Main office) and permission was obtained to conduct the study. To ensure confidentiality of employee's information was kept and was not exposed to third body. Verbal consent was taken and it was approved by ethical review committee.

\section{Consent to publication}

Not applicable.

\section{Competing interests}

The authors declare that they have no competing interests.

Received: 21 Auqust 2019 Accepted: 26 December 2019

Published online: 07 January 2020

\section{References}

1. Sanaye-Pasand M, Zangiabadi M, Fereidunian A. An extended magnetizing inrush restraint method applied to digital differential relays for transformer protection. In: 2003 IEEE power engineering society general meeting (IEEE Cat. No. 03CH37491), vol. 4. New York: IEEE; 2003. p. 2077-82.

2. Ngaopitakkul A, Kunakorn A. Internal fault classification in transformer windings using combination of discrete wavelet transforms and back-propagation neural networks. Int J Control Automation Sys. 2006:4(3):365-71.

3. Genet T. Failure modes and effects analysis to mitigate failure of distribution transformers in Ethiopia. Ethiopia: AAU; 2017.

4. Bashi S, Mariun N, Rafa A. Power transformer protection using microcontroller-based relay. J Appl Sci. 2007;7(12):1602-7.

5. Salahat M, Al-Zyoud A. Modeling of transformer differential protection using programmable logic controllers. Eur J Sci Res. 2010;41(3):452-9.

6. Aziz S, Wang Hz, Peng JC, Ruan JQ. Power sharing of transformer. In: 2018 international conference on power system technology (POWERCON). New York: IEEE; 2018. p. 4438-42.

7. Ambalkar AR, Bhoyar NM, Badarkhe VV, Bathe VB. Automatic load sharing of transformers. Int J Sci Res Dev. 2015;2(12):739-41.
8. Kamel R, Kermanshahi B. Optimal size and location of distributed generations for minimizing power losses in a primary distribution network. Sci Iranica. 2009:16(2):137.

9. Teferra DM. Potential and feasibility study of standalone solar PV/wind/ biogas and biodiesel hybrid electric supply system in Ethiopia. Int J Energy Technol Policy. 2017;13(4):368-77.

10. Gebreegziabher T. Study on smart grid system for improvement of power distribution system reliability case study: Addis Ababa District. Addis Ababa: Addis Ababa University; 2014.

11. Ho W, Hashim H, Hassim M, Muis Z, Shamsuddin N. Design of distributed energy system through electric system cascade analysis (ESCA). Appl Energy. 2012;99:309-15.

12. Phadungthin R, Suwanasri C, Suwanasri T. Failure statistics and condition assessment of power transformer for condition-based maintenance. In: Proceedings of the condition monitoring and diagnosis 2010 conference. 2010.

13. Jiang X. Mathematical modeling and computations for electromagnetic problems. Scientia Sinica Math. 2016:46(3):247-64.

14. Vural AM, Tümay M. Mathematical modeling and analysis of a unified power flow controller: a comparison of two approaches in power flow studies and effects of UPFC location. Int J Electr Power Energy Syst. 2007:29(8):617-29.

15. Saxton D, Grefenstette E, Hill F, Kohli P. Analysing mathematical reasoning abilities of neural models. arXiv:1904.01557. 2019.

16. Shi J, Yang W, Xue F, Qiao W, Yang T, Wang J. Reactive power optimization of active distribution network under parallel condition of solid state transformer and on-load tap changer. In: 2019 22nd international conference on electrical machines and systems (ICEMS). New York: IEEE; 2019. p. 1-6.

17. Bejmert D, Rebizant W, Schiel L. Transformer differential protection with fuzzy logic based inrush stabilization. Int J Electr Power Energy Syst. 2014:63:51-63.

18. Eldin $\mathrm{AH}$, Refaey M. A novel algorithm for discrimination between inrush current and internal faults in power transformer differential protection based on discrete wavelet transform. Electr Power Syst Res. 2011;81(1):19-24.

19. Ali MH. Apparatus for mitigation of adverse effects of geomagnetically induced currents on transformers, ed: Google Patents. 2019.

20. Lagunes ML, Castillo O, Soria J. Optimization of membership function parameters for fuzzy controllers of an autonomous mobile robot using the firefly algorithm. In: Fuzzy logic augmentation of neural and optimization algorithms: theoretical aspects and real applications. Berlin: Springer; 2018. p. 199-206.

21. Spiegel RJ, Bose BK. Fuzzy logic integrated electrical control to improve variable speed wind turbine efficiency and performance. ed: Google Patents. 1997.

22. Wang B, Cheng J, Al-Barakati A, Fardoun HM. A mismatched membership function approach to sampled-data stabilization for TS fuzzy systems with time-varying delayed signals. Signal Process. 2017;140:161-70

23. Yarymbash D, Kotsur M, Yarymbash S, Kylymnyk I, Divchuk T. An application of scheme and field models for simulation of electromagnetic processes of power transformers. In: 2018 14th international conference on advanced trends in radioelecrtronics, telecommunications and computer engineering (TCSET). New York: IEEE; 2018. p. 308-13.

24. Obot OU, Uzoka F-ME. Fuzzy rule-based framework for the management of tropical diseases. Int J Med Engin Inform. 2008;1 (1):7-17.

25. Ramezani S, Memariani A. A fuzzy rule based system for fault diagnosis, using oil analysis results. 2011.

26. De Silva CW. Intelligent control: fuzzy logic applications. Boca Raton: CRC Press; 2018.

27. Paul AK, Shill PC, Rabin MRI, Murase K. Adaptive weighted fuzzy rulebased system for the risk level assessment of heart disease. Appl Intell. 2018:48(7):1739-56.

28. Acharya A, Nahum EM, Tracey JM, Wang X, Wright CP, Xiao Z. Overload protection for SIP servers. ed: Google Patents. 2009

29. Oommen T, Lindgren S. Bubble evolution from transformer overload. In: 2001 IEEE/PES transmission and distribution conference and exposition. developing new perspectives (Cat. No. 01CH37294). New York: IEEE; 2001. vol 1, p. 137-142. 
30. Deaver BJ, Radtke WO. System and method for detecting distribution transformer overload. ed: Google Patents. 2010.

31. De Carne G, Zou Z, Buticchi G, Liserre M, Vournas C. Overload control in smart transformer-fed grid. Appl Sci. 2017;7(2):208.

\section{Publisher's Note}

Springer Nature remains neutral with regard to jurisdictional claims in published maps and institutional affiliations.
Ready to submit your research? Choose BMC and benefit from:

- fast, convenient online submission

- thorough peer review by experienced researchers in your field

- rapid publication on acceptance

- support for research data, including large and complex data types

- gold Open Access which fosters wider collaboration and increased citations

- maximum visibility for your research: over $100 \mathrm{M}$ website views per year

At BMC, research is always in progress.

Learn more biomedcentral.com/submissions 